\title{
Concern regarding the use of extracorporeal membrane oxygenation in the anticipated difficult airway
}

\author{
Robert Chen, MD, FRCPCD
}

Received: 18 February 2019/Revised: 7 March 2019/Accepted: 8 March 2019/Published online: 7 June 2019

(c) Canadian Anesthesiologists' Society 2019

\section{To the Editor,}

I have a concern regarding Dr. Malpas' paper in the Journal that suggests "ECMO (or CPB) is an effective means of providing adequate oxygenation in a patient with severe airway obstruction in which all four fundamental techniques of oxygenation are likely to be unsuccessful". ${ }^{1}$ Although there is intense interest in using extracorporeal membrane oxygenation (ECMO) during resuscitation (socalled "eCPR"), ${ }^{2}$ if improperly protocolized, it could lead to serious morbidity or mortality.

In their paper, veno-arterial ECMO (VA-ECMO) or cardiopulmonary bypass (CPB) was suggested either as a pre-emptive step before complex airway management or as a rescue for "cannot intubate, cannot oxygenate" (CICO). In both techniques, blood is drawn from the patient's venous circulation, pumped through an oxygenator, and returned to the patient through arterial catheterization, typically of the femoral vessels.

In CICO emergencies, without a very low cardiac output (or overt cardiac arrest), VA -ECMO may still allow desaturated blood to return to the right heart, be pumped through the non-ventilated lungs, then through the aortic valve. This deeply desaturated blood can perfuse the coronary circulation and the brain. The ECMO (or CPB) circuit competes (and mixes) with the hypoxic cardiac circulation sending oxygenated blood retrogradely into the

This letter is accompanied by a reply. Please see Can J Anesth 2019; 66: this issue.

\section{R. Chen, MD, FRCPC ( $₫)$}

University of Ottawa Heart Institute, Ottawa, ON, Canada

e-mail: rchen@ottawaheart.ca aorta, initially oxygenating the legs and abdomen. This parallel circulation, when the mixing of oxygenated and de-oxygenated blood occurs in the aortic arch, is well described and can result in a "harlequin syndrome" ${ }^{3}$ with the right carotid artery receiving de-oxygenated blood from the heart and the left carotid artery receiving oxygenated blood from the ECMO circuit. Even when VA-ECMO is used for heart failure, aortic valve opening (providing evidence for transpulmonary flow) is often seen. The harlequin-like asymmetric cerebral desaturation is made worse by poor ECMO venous drainage that can occur with suboptimal venous catheter placement if both cavae and the right atrium are incompletely drained. Inadequate arterial flow (due to small catheter size) can also lead to suboptimal ECMO circuit blood flow that further favours proximal desaturation.

Ironically, the brain will become better oxygenated once cardiac arrest occurs (from coronary artery desaturation) as the native, parallel, desaturated circulation shuts down. Nevertheless, once the team "gets the patient back", the patient's brain is again at risk of desaturating.

Although the authors review the use of ECMO in airway emergencies, there is excessive focus on VA-ECMO and CPB. ECMO for CICO should arguably follow the same standards as ECMO for oxygenation failure in severe lung disease. VV-ECMO is the suggested modality with inferior vena cava drainage and superior vena cava (SVC) return cannula placed with fluoroscopy or transesophageal echocardiography. Other veno-veno cannulation strategies exist, which include femoral-femoral and the Avalon cannula (placed via the SVC), all of which offer advantages to VA-ECMO.

Veno-arterial-ECMO or CPB as a rescue may harm the brain in the setting of respiratory arrest without a cardiac arrest. As a profession with leadership roles in airway and 
ECMO, it may be time to create standards and guidelines for the use of the resuscitative modalities in CICO, or adopt guidelines and standards already available for ECMO in respiratory failure without cardiac failure. We need to be specific in our ECMO recommendations based on a fundamental understanding of ECMO principles to avoid patient harm.

Conflicts of interest None declared.

Editorial responsibility This submission was handled by Dr. Hilary P. Grocott, Editor-in-Chief, Canadian Journal of Anesthesia.

\section{References}

1. Malpas G, Hung $O$, Gilchrist A, et al. The use of extracorporeal membrane oxygenation in the anticipated difficult airway: a case report and systematic review. Can J Anesth 2018; 65: 685-97.

2. Grunau B, Scheuermeyer FX, Stub D, et al. Potential candidates for a structured Canadian ECPR program for out-of-hospital cardiac arrest. CJEM 2016; 18: 453-60.

3. Rupprecht L, Lunz D, Philipp A, Lubnow M, Schmid C. Pitfalls in percutaneous ECMO cannulation. Heart Lung Vessel 2015; 7: 320-6.

Publisher's Note Springer Nature remains neutral with regard to jurisdictional claims in published maps and institutional affiliations. 